\title{
Forensic toxicological analysis of hair: a review
}

\author{
Muhammad Usman ${ }^{1 *}$ D, Abid Naseer', Yawar Baig', Tahir Jamshaid', Muhammad Shahwar' and Shazia Khurshuid ${ }^{2}$
}

\begin{abstract}
Analysis of hair provides useful information regarding drug addiction history or drug toxicity. Keeping in view some important applications of hair analysis, a lot of work done in the past few decades has been reviewed in this article. When compared with other biological samples, hair provides a larger window for drug detection. Drugs get deposited in hair through blood circulation by various mechanisms, after its administration. The deposited drug is much stable and can be detected after a longer period of time as compared with other biological samples, e.g., saliva, blood, and urine. Moreover, segmental analysis can depict multiple or single drug administration by using sensitive analytical techniques. Complex methods for drug extraction and the high cost of analysis are some drawbacks of hair analysis. LC-MS and GC-MS are the prominent among other techniques of choice due to high sensitivity. In this review, detailed knowledge about the drug deposition, extraction, analysis, and application of results in forensic and clinical cases have been discussed.
\end{abstract}

Keywords: Forensic science, Toxicology, Hair analysis, Narcotic drugs, Drug of abuse

\section{Background}

During the last few decades, tremendous research work has been done to investigate the different drugs of abuse and their metabolites in different types of biological samples, e.g. saliva, sweat and hair. In a number of countries, biological samples other than urine, are being explored intensively for workplace drug testing, providing information about chronic intoxication, awarding a driving license, clinical toxicology, in criminal justice, in the treatment of addicted patients, postmortem toxicology studies, solving drug-facilitated crimes and in child protection cases (Allibe et al. 2017; Baumgartner et al. 1979; Khajuria and Nayak 2017). For analysis of new psychoactive substances, hair testing is a good complement to urine testing (Kintz 2017a; Montesano et al. 2017).

During the 1960s and 1970s, the hair was analyzed for the investigation of heavy metals by atomic absorption spectroscopy (AAS). Since at that time, analytical techniques were not sensitive enough to analyze organic compounds particularly the drugs from hair. However, by the use of radioactive isotope-labeled drugs, it was confirmed that they circulate through blood circulation and deposit in hair. In 1979, the first research article was published regarding the analysis of hair from heroin users. Morphine, a metabolite of heroine, was found in the hair of addicts (Kintz 2017b). It was also found that the concentration of drug varied along the length of the hair shaft, which could be correlated with the time period of abuse. Nowadays, GC-MS is commonly used and reported method for analyzing a drug of abuse from the hair of addicts.

The major advantage of hair drug testing over blood and urine drug testing is its better inspection window. Hair drug testing has a better inspection window when compared with blood and urine drug testing, which can be characterized as its major advantage (2-4 days for drug analysis from blood and urine for most of the drugs against weeks to several months, depending upon the length of hair) (Hegstad et al. 2008). Blood analysis and urinalysis give short-term information related to drug addiction whereas long-term drug history can be traced by hair analysis (Saitoh 1969).

\footnotetext{
* Correspondence: usman.iqba@pfsa.gop.pk; m.usman.iqbal9009@gmail.com

${ }^{1}$ Narcotic Unit, Punjab Forensic Science Agency, Lahore 53700, Pakistan

Full list of author information is available at the end of the article
} 


\section{Main text}

\section{Structure and types of hair}

Hair is mainly composed of protein, which may range from 65 to $95 \%$ (keratin), lipids 1-9\%, 15-35\% water, and less than 1\% minerals (Kintz 2017b). Its texture, color, and composition vary from person to person. Different types of minerals accumulated in the hair may range from 0.25 to $0.95 \%$. About 5 million hair follicles are present in an adult. Out of these 5 million hair follicles, approximately 1 million are found in the head. Hair follicles are rooted 3-4-mm deep in the skin, in the epidermis of epithelium (Mangin 1996). The total hair length covers its bulb rooted in the follicle through the shaft and ends at its tip. The shaft is comprised of three layers, i.e., cuticle, cortex, and medulla. Cuticle has some ability to maintain its structural features for a longer period of time and also have some resistance to chemical decomposition. Cortex is the second layer lying under the protective covering of cuticle. The cortex derives its major forensic importance from the fact that it is embedded with the pigment granules, which gives hair its characteristic color. The color, shape, and distribution of these granules provide important points of comparison among the hairs of different individuals. The medulla is a collection of cells that looks like a central canal running through the hair. In many animals, this canal is a predominant feature, occupying more than half of the hair diameter. The presence and appearance of medulla vary from individual to individual and even among the hairs of the same individual. Medullae may be classified as continuous, interrupted, fragmented, or absent. $\mathrm{Hu}-$ man head hairs generally exhibit no medullae or have fragmented ones and they rarely show continuous medullation (Kronstrand et al. 1999).

There are different types of hairs that can be used as a substitute for drug analysis when there are no scalp hair, e.g., axillary (armpit), pubic hair, and arm hair. A number of studies have been performed to find out the differences in concentrations of drug in various types of hairs from the same individual. When the concentration levels of morphine, methadone, phenobarbital, and cocaine were compared in different types of hairs, the highest level of drug quantity was found in axillary hair and lowest one was found in the scalp hair. In another study, the concentration of morphine was determined in different hair types: $0.4-24.2 \mathrm{ng} / \mathrm{mg}$ was found in axillary hair, $0.6-27.1 \mathrm{ng} / \mathrm{mg}$ in scalp hair, and $0.8-1.34 \mathrm{ng} / \mathrm{mg}$ in pubic hair. The remarkable differences in concentration of drug are due to the improved blood supply, telogen-anagen ratio, difference in growth rate, and different numbers of apocrine gland. Different types of hairs grow at different rates, e.g., pubic hair $0.3 \mathrm{~mm} /$ day and axillary hair $0.4 \mathrm{~mm} /$ day. The growth rate of beard hair is $0.27 \mathrm{~mm} /$ day, and it is thought to be the appropriate choice for drug analysis. Beard hair can be collected daily for investigation of the rate of drug deposition (Cone et al. 1991).

\section{Growth of hair}

Human hair grows in three developmental stages. The shape and size of the hair root are determined by the growth phase in which the hair happens to be. The three phases of hair growth are the anagen, catagen, and telogen phases. The anagen phase may last up to 6years. During this phase, the root remains attached to the follicle for continued growth, giving the root bulb a flame-shaped appearance. The catagen phase may proceed from 2 to 3 weeks. During this phase, hair continues to grow but at a retarded growth rate. In the catagen phase, roots acquire an elongated appearance as the root bulb shrinks and are pushed out of the hair follicle. Once the hair growth stops, the telogen phase begins and the root takes on a club-shaped appearance. By the next 2 to 6 months, the hair is pushed out of the follicle, causing the hair to shed off naturally (Baumgartner et al. 1989) (Khajuria et al. 2018).

The growth of hair does not remain continuous throughout the course. It is a cyclic process in which hair growth phase alternates with dormant or no growth phase. The actively growing follicles are in the anagen phase. The head hairs grow at a rate of $0.6-1.42 \mathrm{~cm} /$ month or $0.22-0.52 \mathrm{~mm} /$ day. The rate of growth of hair depends on location and type of hair. After the growth phase, the hair follicle enters in catagen phase. In this phase, the hair shaft stops growing and shed off (Cartmell et al. 1991; Kintz 2017b).

\section{Mechanisms of drug incorporation}

The simple passive transfer is the simplest model that explains the deposition of a drug into the hair. According to this model, drugs incorporate in the hair by the passive diffusion from the growing cells in hair root, and when the keratogenesis occur, the drug is transferred to the hair shaft in a tightly bound form. The deposition of drug in the hair depends on the concentration of drug in blood if the rate of hair growth is constant. This model describes that segmental analysis of hair can predict the presence of the drug in the blood for a specific time interval.

Complex multi-compartment model is another model describing the drug deposition mechanism in hairs. This model is more accepted than the previous one. According to it, the drugs incorporate into the hair in three different ways.

Through blood circulation during hair formation Through sweat and sebum gland after the formation of hair 
Through the external environment after the formation of hair

Several studies support this concept that drug incorporates into the hair after its formation. The drug which is deposited after the formation of the hair is loosely bound and can be removed easily by washing (Cirimele et al. 1995).

Intradermal transfer of lipid soluble drug is another possible way of drug incorporation in the hair. Cocaine and its metabolites are accumulated into the skin layers and subsequently into the hair by this mechanism (Sachs and Kintz 1998). Among all the models, the multi-compartment model is the best to explain the drug incorporation into the hair. Still, there are many areas which are to be investigated, e.g., exact mechanism and factors affecting the deposition of drug in hair. (Franceschin et al. 1987; Pragst and Balikova 2006) (Khajuria et al. 2018). It is important to note that the nature of substance/drug being incorporated, i.e., its structure and chemical properties as well as physiological/physical characteristics of individual strongly affect the dominant mechanism of drug deposition. Comparison of hair drug analysis of Caucasian and African American showed no difference (Huestis et al. 2007). Villain found that drug deposition due to contamination cannot take place in the hair, even if a person is working daily in a controlled drug environment with minimal hygiene and cautions (Villain et al. 2010).

The linkage between hair pigmentation and the concentration of drug deposited can be revealed by the fact that white hairs have the least concentration of drug as compared with black hairs, having the highest drug concentration. DeLauder investigated the binding of the drug with hair using fluorescence microscopy and found that negatively charged drugs, e.g., THC-COOH, do not incorporate freely into the hair. The preferential attachment of the drug to hair is due to the electrostatic forces of attractions between hair and drug of abuse.

\section{Stability of deposited drug}

The drug incorporated in the hair is very much stable in favorable conditions, e.g., ambient temperature and dry atmosphere. Opiates were detected in hair shaft of Victorian poet John Keats. The analysis of the hair was performed 167 years after the death of John Keats (Jeger et al. 1991). The scalps were tested positive for benzoylecgonine in the hairs of eight Peruvian and Chilean mummies of ages of 2000BC to 1500AD (Khajuria et al. 2018). In a study, hair samples from the de-addiction center were collected and analyzed to check the stability of drugs in the hairs. Hair samples were analyzed after 90 days of drug abuse and quantified positively. It showed that drugs are quite stable and have long detection time (Khajuria and Nayak 2013).

Although drugs are very much stable in the hair, some cosmetic treatments may damage the hair and pre-deposited drugs as well. The hair cuticle damage continuously due to many factors, e.g., sunlight, weather, pollution and cosmetic treatments, dyeing, waving, relaxing, and shampooing. As a result of research, it was found that there is no significant effect of shampooing on the drug deposited in the hair (Kintz et al. 1995b). In comparison with the original concentration of drug in the hair, $50-80 \%$ of drug concentration reduces dramatically due to cosmetic treatments. The cosmetic products include strong bases, which damage hair, reduce drug contents, and affect the stability of the drug (Kalasinsky et al. 1994).

\section{Dose concentration relationship}

The dose of the abused drug and its concentration in the hair is still an under research topic. The chronic abusers take different amounts of drugs in daily routine. So, huge data related to individual differences is needed to determine the dose and concentration relationship (Kintz et al. 2000a). Fragile relationship between dose and concentration can be expounded by the following:

- Dose of the drug is uncertain

- Percentage purity of abused drug is unknown

- Deposition of the drug in the hair also vary from person to person

It is thought that possibly the genetic effect related to melanin concentration and porosity may be related to drug concentration in the hair (Khajuria et al. 2018).

\section{Collection of hair specimen}

There is no standard method for the collection of a hair sample from addicted patients or from victims for forensic analysis. The hair samples are collected randomly from different body parts. Vertex posterior (back of the head) is the best area for sample collection (Kintz 2017b), due to the following:

- Most of the hairs exist in the same growth phase

- The growth rate of most of the hairs is also the same in this region

- Less influence of age and sex

Hair is cut from near the scalp surface; location of hair is also noted. The hairs are stored in an envelope, aluminum foil, or a plastic zip lock bag and stored at ambient temperature. The amount of hair sample taken depends on the drug to be tested. Also, it depends on the laboratory in which drug testing is going to be 
carried out because different labs have different methods of extraction and analysis. The sample size mentioned in most of the research literature ranges from $200 \mathrm{mg}$ to a single hair, but the hair should be cut as closely to the scalp as possible. Hair shaft of about $3 \mathrm{~cm}$ of length is taken, when segmental analysis of hair is to be performed. Length of $1 \mathrm{~cm}$ corresponds to 1-month growth (Cooper et al. 2012; Klug 1980) (Khajuria et al. 2018).

\section{Washing/decontamination procedure}

Contaminants on the surface of the hair create a problem during analysis. Contaminants can be care products (hair gel), sweat, and drug contaminants from the environment, or anything else. If these contaminants are not properly removed, they can interfere with the analysis and alter the possible results (Cooper et al. 2012; Moeller 1992). Baumgartner and Hill described that false-positive results can be prohibited by the external decontamination of the hair. To remove externally bounded contaminants, washing step prior to extraction is used, but there is no uniform/standard procedure for decontamination (Blank and Kidwell 1995). The most commonly used chemicals for washing are detergents (i.e., shampoo, surgical scrubbing solutions), surfactants ( $0.1 \%$ sodium dodecyl sulfate), phosphate buffer (Hegstad et al. 2008), and organic solvents (i.e. acetone, diethyl ether, methanol, ethanol, dichloromethane (Mercolini et al. 2008), hexane, pentane) (Khajuria et al. 2018). Society of Hair Testing recommends that a hair decontamination procedure should include both an organic and aqueous washing step. Studies have shown that the most effective organic solvent was methanol and the most effective aqueous solvent contained sodium dodecyl sulfate detergent (Mantinieks et al. 2018).

Most commonly single washing is used, although sometimes hairs are washed twice, to remove external contaminants as much as possible (Baumgartner et al. 1989). In hair analysis, the metabolites of drugs are analyzed, which would not exist in external contamination otherwise. Metabolites are only produced as a product in the process of metabolism (Kauert and Röhrich 1996). Metabolites are not present in the illicit drug. Their existence in the hair sample could not be due to external contamination. So, the presence of metabolites would confirm the drug intake. Several types of research demonstrated that when cannabis, crack, and heroin were smoked, the external contamination could occur (Tagliaro et al. 1997b).

\section{Hair digestion procedures}

It is essential that the drug should be solubilized before analysis. The process of solubilization should be set in a way that the drug and its metabolites remain intact (not lost or altered). Special care should be paid to the drugs which are chemically unstable and are lost in the extraction process. For example, 6-acetylmorphine (6-AM) is converted to morphine and cocaine is converted to benzoylecgonine (Pötsch et al. 1997). The hair samples prior to analysis can be cut into segments or crushed in a ball mill. For dissolution, there are different preparation techniques which may involve one of the following procedures:

- Incubation in an aqueous buffer and analysis using immunological techniques, mostly radioimmunoassay (RIA).

- Incubation in an acidic or basic solution followed by liquid-liquid extraction or solid-phase extraction and analysis with chromatographic techniques.

- Incubation in an organic solvent (generally methanol with or without hydrochloric acid), liquid-liquid extraction, or solid-phase extraction and analysis with chromatographic techniques.

- Digestion in an enzymatic solution, liquid-liquid extraction, or solid-phase extraction and analysis with chromatographic techniques (Sachs and Arnold 1989) (Khajuria et al. 2018).

When the hair is digested by incubating in sodium hydroxide solution, the protein contents are damaged. The parameters like the temperature of incubation, time of incubation, and concentration of sodium hydroxide solution are to be set carefully. Drugs which are chemically unstable cannot be extracted by alkaline hydrolysis. Drugs like anabolic steroids (esters), benzodiazepines, cocaine, and 6-AM should not be extracted by the alkaline method because these are hydrolyzed in strong alkaline conditions. To extract 6-AM and cocaine, acid hydrolysis method should be used. In the acid hydrolysis method, the hair sample is incubated at room temperature overnight in $0.1-\mathrm{M} \mathrm{HCl}$ solution or at $120^{\circ}$ $\mathrm{C}$ for $30 \mathrm{~min}$ in $0.6-\mathrm{M} \mathrm{HCl}$ solution (Cirimele et al. 1996b). The simplest extraction procedure is the organic solvent incubation method. In this method, the hairs are digested in an ultrasound bath for several hours at $45^{\circ} \mathrm{C}$ using ethanol or methanol as solvent. After evaporating the organic solvent, the sample can be analyzed directly by GC-MS. By using this method, it is possible to analyze the unstable drugs like 6-AM in the hair of heroin addicts. The hair of cocaine and heroin addicts can also be processed by enzymatic digestion process. In this method, hairs are treated with a solution of pronase, arylsulfatase, proteinase $\mathrm{K}$, or glucuronidase. These enzymes digest hair by acting on hair protein (keratin) without altering or destroying the concentration of drug and its metabolites (Klein et al. 2000). Enzymatic hair digestion may show false-positive results for ELISA analysis (Barker et al. 2017). Wang used a mixture of 
methanol, acetonitrile, and ammonium formate for extraction of 116 drugs and their metabolites from hair (Wang et al. 2017).

\section{Drug analysis}

Baumgartner analyzed morphine in the hairs of addicts to find opiate abuse history. He used RIA to check morphine in the hair (Klein et al. 2000). After the research of Baumgartner, a lot of work was done in this field. In most of these studies, RIA, GC-MS, or both of them were used. Chromatographic techniques are best to identify and quantify drugs due to high capacity for the separation of components. If some chromatographic technique is coupled with mass spectrometry than the detection window becomes broader in terms of specificity and sensitivity (Cirimele et al. 1996b). Different types of methods used for drug analysis are given below:

\section{Immunoassays}

Immunological methods are used as a screening test to check the presence of drug. The extraction procedure should be compatible with the preliminary screening test, so that detergents used for washing and chemicals used for digestion do not interact with the assay. If chemical hydrolysis process is used, then the neutralization should be done after extraction. Before the addition of immunoassay, the hair matrix must be destroyed. The destruction of hair protein should be done carefully so that it may not destroy the deposited drug and its metabolites (Cirimele et al. 2000). Immunological methods are not used for quantification; these are used only to check the presence of a drug. Immunological kits are not designed for a specific drug, but to analyze a group of drugs and their metabolites (Edder et al. 1994; Shearer et al. 2006). The most common method used for drug screening in hair samples is radioimmunoassay method (RIA) (Cone 1996). Initial screening test using RIA showed false-positive test to a great extent for cannabinoids, so RIA is not suitable for preliminary investigation of cannabinoids (Quintela et al. 2000). Fluorescence polarization immunoassay (reported in 1987 for the first time) is also used for initial screening (Forman et al. 1992). Musshoff employed two commercial ELISA and immunoassay kits to find out the cut-off values for different drugs in hair samples. Hair samples from drug addicts of amphetamine, methamphetamine, benzodiazepines, cocaine, cannabis, methadone, and opiates were analyzed. ELISA kit showed a sensitivity of $98 \%$ for methadone, $94 \%$ for both the benzodiazepines and opiates, $92 \%$ for methamphetamine, and $91 \%$ for amphetamine. ELISA test is not useful for tetrahydrocannabinol. The cut-off value for THC was found to be $0.02 \mathrm{ng} / \mathrm{mg}$. Immunoassay kit was found to be useful only for cocaine and morphine. New cut-off value was investigated for these drugs, which came out to be $0.1 \mathrm{ng} / \mathrm{mg}$ (Musshoff et al. 2012). The results obtained by immunoassay should be confirmed by some confirmatory technique. GC-MS or LC-MS is commonly used for confirmation (Cuypers and Flanagan 2018).

\section{Chromatographic methods}

Chromatographic methods are used for the confirmation of drugs. By using these techniques, components of a mixture are separated and detected subsequently. Chromatographic techniques are used for the quantification of drugs and their metabolites from the hair sample. Klug separated morphine from the hair sample of addicts by using thin layer chromatography (TLC) and quantified the drug by fluorimetery method (Franceschin et al. 1987). By using TLC, quantification can also be done by densitometry (Goullé et al. 2003).

\section{Gas chromatography-mass spectrometry}

Gas chromatography (GC) separates a mixture of compounds into individual components and the detector coupled with GC identifies each component. There are different types of detectors which can be coupled with $\mathrm{GC}$, i.e., flame ionization detector and mass spectrometer. Flame ionization detector (FID) is not much useful for the detection of a drug in the hair (Henderson et al. 1998). For best results, mostly the GC-MS is used for hair analysis. By using GC-MS, a number of drugs can be detected, e.g., amphetamines, benzoylecgonine, cannabinoids, cocaine, codeine, methadone, morphine, and other opiates (Henderson et al. 1996; Johansen and Jornil 2009; Meng et al. 2009). Analysis using GC-MS involves some complex sample extraction and derivatization steps; still, it is an important technique for qualitative analysis of drugs in forensic science. BSTFA is one of the derivatizing agents used for drug analysis (Orfanidis et al. 2017).

For the quantitative analysis of tetrahydrocannabinol (THC), cannabinol (CBN), and cannabidiol (CBD), hairs are extracted by digestion in $1 \mathrm{M} \mathrm{NaOH}$ at $95^{\circ} \mathrm{C}$ for $10 \mathrm{~min}$ followed by solvent extraction using n-hexane-ethyl acetate. The extracted drug is analyzed on GC-MS. The method showed the lowest LOD for THC, CBD, and CBN, i.e., 0.006, 0.005, and $0.002 \mathrm{ng} / \mathrm{mg}$, respectively (Kim et al. 2005). The extraction of CBD, $d^{9}$-tetrahydrocannabinol $\left(d^{9}-T H C\right)$, $\mathrm{CBN}$, and 11-nor- $\mathrm{d}^{9}$-tetrahydrocannabinol-carboxylic acid $\left(\mathrm{d}^{9}-\mathrm{THC}-\mathrm{COOH}\right)$ from human hair can also be done by the hydrolysis of hair. For hydrolysis, hairs are incubated in an aqueous solution of b-glucuronidase/arylsulfatase for $2 \mathrm{~h}$ at $40{ }^{\circ} \mathrm{C}$. After the hydrolysis, the sample is extracted with chloroform/isopropyl alcohol. After the derivatization, the extracted drugs are analyzed by GC-MS in electron impact mode (GC-MS-EI) or GC-MS in negative ion chemical ionization mode (GC-MS-NCI). It has been found that 
GC-MS-NCI shows better result than GC-MS-EI for the quantification of $d^{9}-\mathrm{THC}-\mathrm{COOH}$ (Baptista et al. 2002). Cirimele proposed a simple, rapid, and free of derivatization screening procedure for detection and quantification of THC, CBD, and CBN in hairs of long-term drug abusers. Hair samples were rinsed with methylene chloride, hydrolyzed by sodium hydroxide, extracted with n-hexane-ethyl acetate mixture, and finally analyzed using GC-MS-EI. The mean concentrations were $0.44 \mathrm{ng} / \mathrm{mg}, 0.13 \mathrm{ng} / \mathrm{mg}$, and $0.15 \mathrm{ng} / \mathrm{mg}$ for CBD, CBN, and THC respectively (Cirimele et al. 2000; Cirimele et al. 1996b).

Hair analysis for amphetamine-type stimulant (ATS) and a number of related drugs (i.e., methylenedioxymethamphetamine, $\mathrm{N}$-methylbenzodioxazolylbutanamine) can also be performed using GC-MS (Cirimele et al. 1999), but the drugs need to be derivatized prior to the analysis. There are a number of research articles in which acid or base hydrolysis is done. After hydrolysis, liquid-liquid extraction is normally performed to separate the drug from the hair. Most of the researches used the same derivatization procedures (Negrusz et al. 2002; Negrusz et al. 2001). Hair samples are washed and digested. The drug is extracted by liquid-liquid extraction using ethyl acetate and derivatized with heptafluorobutyric anhydride (HFBA). The analysis using GC-MS in SIM mode-detected MDMA with LOD $5.0 \mathrm{ng} / \mathrm{mg}$ (Karačonji and Brajenović 2014). Supercritical fluid extraction (SFE) can also be used for extraction of amphetamine from hair for both the qualitative and the quantitative analysis by GC-MS (Allen and Oliver 2000). Trifluoroacetyl-prolyl chloride is a chiral derivatizing agent. It is used for separation and detection of R and S isomers of ATS. After derivatization and liquid-liquid extraction by hexane, the sample is analyzed using GC-MS in SIM mode. A study on this method found the LOD for amphetamine, methamphetamine, and methylenedioxyamphetamine (MDA) to be $0.1 \mathrm{ng} / \mathrm{mg}$ each and $0.2 \mathrm{ng} / \mathrm{mg}$ for both the MDEA and MDMA (Strano-Rossi et al. 2009). Amphetamine is the major metabolite of methamphetamine in the body, which is produced as a result of metabolism after the ingestion of the drug. The drug ratio of amphetamine and methamphetamine has been determined to confirm that which drug was abused. MDMA (ecstasy) was first investigated in 1992 in the hair of abusers; the concentration was $0.6 \mathrm{ng} / \mathrm{mg}$ (Kintz et al. 2000b).

In the case of heroin abuse, codeine, morphine, and 6-acetylmorphine (6-AM) are detected. If morphine is abused than both, morphine and 6-AM (morphine glucuronides are the metabolites of heroin) would be detected in samples and if codeine exposure also occurred than both, the codeine and morphine would be present. To confirm that which drug was actually abused, it is necessary to quantify the drugs in a sample (Kidwell 1993). If the concentration of morphine is higher than that of codeine, then heroin or morphine might have been abused, and if codeine concentration is higher than that of morphine, it might be a codeine abuse case. To differentiate between morphine and heroin abuse cases, the concentration of 6-AM is determined. The concentration of 6-AM would be greater in the case of heroin abuse (Kintz et al. 1995c). In the case of opioids, the alkaline extraction procedure should not be used because of low chemical stability and inter-conversion of opioids in alkaline conditions (Cirimele et al. 1996a).

\section{Liquid chromatography-mass spectrometry}

Liquid chromatography-mass spectrometry had been among the widely used techniques for hair analysis. It is advantageous as it is highly sensitive and it can detect even a trace amount of drug in the hair sample without derivatization (Huang et al. 2009; Pelander et al. 2008). Due to the dramatic improvements, instrumentation based on liquid chromatography-tandem mass spectrometry (LC-MS/MS) makes it possible to detect a little amount of almost every possible drug in the hair, and it remains possible even after a single-dose administration. Therefore, LC-MS/MS is gradually replacing the gas chromatographic techniques in both screening and confirmation procedures. Nowadays, it is increasingly acknowledged as the technique of choice for hair analysis (Di Corcia et al. 2018; Leung et al. 2018). After washing and digestion, the drugs are extracted with some suitable solvent by liquid-liquid extraction and then by SPE. The extracted drug is directly injected into LC-MS for analysis (Lendoiro et al. 2012). Identification and quantitation of tetrahydrocannabinol can be done by the analysis of 11-nor-9-carboxy-D9-tetrahydrocannabinol which is a metabolite of THC, and it is found only in the body. So, the presence of 11-nor-9-carboxy-D9-tetrahydrocannabinol allows us to find the chronic user of THC and also excludes the chances of external contamination. After liquid-liquid extraction, chromatographic separation can be done by using a reverse phase column in LC-MS/MS (LOD $3 \mathrm{pg} / \mathrm{mg}$ ). It can be used to monitor chronic drug users. (Kintz et al. 2004; Machnik et al. 1999; Mercolini et al. 2013; Möller et al. 1992). It was found that the last intake of THC can be detected till 3 months in hair sample (Khajuria and Nayak 2014).

Quantitative analysis of benzodiazepines from the hair of criminals can also be performed by using LC-MS/MS technique (Xiang et al. 2011). Miller et al. extracted benzodiazepines from hair by a simple method. Hairs were decontaminated by washing with $0.1 \%$ solution of sodium dodecyl sulfate, distilled water, and dichloromethane. The decontaminated hairs were extracted by SPE, after the overnight soaking in $25 \%$ methanol and ammonium hydroxide mixture (20:1). The extract was analyzed for benzodiazepines on LC-MS/MS (Miller et al. 
2006). VMA-T extracted solution can be used further for LC-MS analysis (Baumgartner et al. 2012).

Ketamine and norketamine (a metabolite of ketamine) can be extracted by ultrasonication for $4 \mathrm{~h}$ in $0.01 \%$ solution of formic acid for analysis on LC-MS/MS. The limit of detection and limit of quantification for the method is $0.1 \mathrm{ng} / \mathrm{mg}$ (Tabernero et al. 2009).

For the analysis of cocaine, the drug and its metabolites are extracted using SPE after digestion of the hair by incubating in $0.1 \mathrm{M} \mathrm{HCl}$. The mixture of phosphate buffer ( $\mathrm{pH}$ 3.0), methanol, and acetonitrile is used as a mobile phase in LC-MS (Mercolini et al. 2008). LC-MS/ MS can also be used for simultaneous detection and quantitation of cocaine, benzoylecgonine, codeine, morphine, and 6-acetylmorphine. For simultaneous analysis, drugs are extracted with methanol after pulverization. The extract is injected into LC-MS/MS, and methanol and ammonium acetate $(\mathrm{pH} 4.00)$ are used as mobile phase with a flow rate of $500 \mu \mathrm{L} / \mathrm{min}$. The limit of detection for codeine, morphine, and 6-acetylmorphine is 10 $\mathrm{pg} / \mathrm{mg}$ and for cocaine and benzoylecgonine $1 \mathrm{pg} / \mathrm{mg}$ (Henderson 1993; Kikura et al. 1997; Miller et al. 2008). Forensic hair drug testing showed extended usage of a drug for regular cocaine users. Hair testing did not show positive results immediately after the drug administration. Results of hair analysis are used along with the results of urine and blood analysis (Harrison and $\mathrm{Fu} 2014$ ).

For the detection of amphetamine, methamphetamine, and their metabolites using LC-ESI-MS, special $\mathrm{N}$-vinylacetamide containing hydrophilic polymer online extraction column and SCX semi-micro LC column in electrospray ionization interface has been applied successfully. Dibenzylamine was used as an internal standard. Analysis on SIM mode showed a lower LOD, i.e., $0.02 \mathrm{ng} / \mathrm{mg}$ compared to LOD $0.1-0.2 \mathrm{ng} / \mathrm{mg}$ on full-scan mode (Miki et al. 2003).

\section{Other hair analysis techniques}

Capillary zone electrophoresis (CZE) can be used for the determination of the quantity of morphine and cocaine in the hair of addicts (Höld et al. 1999). Un-extracted hair can be examined by infrared microscopy. Infrared spectra of cuticle, cortex, and medulla of a single hair can show the drug exposure. Fourier transform infrared microscopy (FTIR) is more sensitive than GC-MS (Jurado et al. 1995). The presence of organic compounds can be detected by fluorescence microscopy which could be a good alternative to chromatographic procedures (Jeger et al. 1991). Gottardo employed time-of-flight mass spectrometry and capillary electrophoresis-electrospray ionization, first time for the detection of drugs of abuse (cocaine, codeine, ephedrine, morphine, MDMA, methamphetamine, MDA, amphetamine) from the hair sample. The quantity of drug was also determined.
Results showed moderate accuracy, but the method is still found useful for the analysis of drug of abuse from hairs (Gottardo et al. 2007).

\section{Applications of hair analysis Drug-facilitated sexual assaults}

The cases of drug-facilitated sexual assaults (DFSA) are normally reported late due to the effects of drugs used. The victim becomes unable to understand what happened and does not remember anything related to the event, due to the effects of "date rape drugs." When she realizes the situation, it gets too late to investigate the drug used in crime from urine or blood (Dinis-Oliveira and Magalhães 2013; LeBeau and Montgomery 2010). Different drugs, e.g., ketamine, rohypnol, and GHB are used for the crime (Busardò et al. 2018). Drugs used for DFSA are converted to metabolites, so their presence cannot be detected in urine or in blood. Hair samples from the victim of a DFSA can be analyzed after 1 month of aggression. The parent compound cannot be detected but the metabolites can (Maublanc et al. 2014; Wang et al. 2018). Kuwayama successfully used internal temporal markers (ITMs) micro-segmental hair analysis technique for the determination of specific day of drug ingestion (Kuwayama et al. 2018).

\section{Verification of drug history through sectional analysis of hair}

To measure a drug for a relatively short period of time, sectional analysis of hair is performed by cutting hair into short fragments. It is important to cut the hair as close to the skin as possible. When hairs are cut, it is also very important to keep the information of relative position of hair fragments. As farther away from the root hair, the quantitative analysis of hair sections should be done carefully. This cross-sectional analysis provides reflective calendar of a person's drug abuse history (Kintz 2017b; Kintz et al. 1999). The information can also be used to find the level of drugs abused during the latest short period before admitting to a rehabilitation center. The analysis of sections of hair for abused drugs is most widely used in rehabilitation centers to find out the previous history of abuse (Negrusz et al. 2002). The shift from one drug to another can also be confirmed accurately, e.g., from heroin to codeine or ethyl-morphine. The drugs like cannabinoids (which have extended half-lives and remain in the body for longer periods of time, i.e., for weeks and months) should not be analyzed by sectional analysis for a particular period of drug abuse and also not for the comparison of addict patients (Rothe et al. 1997).

By providing information on exposure to drugs over time, hair analysis may be useful in verifying self-reported histories of drug use in any situation in 
which a history of past rather than recent drug use is desired (Sachs 2000). In addition, hair analysis might also be useful when a history of drug abuse is difficult or impossible to obtain, such as from psychiatric patients (Jurado et al. 2000; Uhl 1997).

\section{Determination of gestational drug exposure}

Maternal drug abuse is a health hazard for the fetus, and the effects of methadone, cocaine, PCP, opiates, cannabinoids, amphetamines, ecstasy, benzodiazepines, and nicotine are well documented (Pragst et al. 2015). It is very difficult to determine the drug in hairs of young children due to more porosity and finer than hairs of adults (Kintz et al. 2017). In 1987, Parton reported for the first time the fetal cocaine exposure by hair analysis (obtained from 15 babies) using RIA. Other studies have demonstrated the placental transfer of maternal haloperidol and the presence of nicotine, morphine, amphetamine, and benzodiazepines in neonatal hair (Thieme et al. 2000). It has been suggested that fetal accumulation of cocaine and its metabolites follows a linear pattern within clinically used doses and that a dose-dependent transfer of maternal nicotine to the baby exists. Analysis of new-born hair may overcome the disadvantages of currently used methods to verify drug abuse, such as maternal self-reported drug history, maternal urinalysis, and analysis of the urine or the meconium of the baby at the time of delivery (risk of false-negative information during the preceding 1-3 days) (Kintz et al. 1993).

\section{Dope testing}

The analysis of hair segments can prove the regular use of a drug for anabolic purposes. The scientific literature does not contain many articles that deal with the identification of anabolic steroids in the hair, as only a few studies have been undertaken (Moeller et al. 1992). A professional male boxer was found to contain clostebol metabolite during his urine testing. Later, hair samples collected from his arm and leg confirmed the clostebol abuse (Salomone et al. 2018). In a well-known fatal case of a male bodybuilder who was known to abuse various anabolic steroids regularly and died of a cardiac arrest at the age of 32, testosterone esters, nandrolone decanoate, metenolone, and methandienone were identified in the hair (Moeller et al. 1993). Similarly, French customs officials arrested two bodybuilders with 250 ampoules and more than 2000 tablets of anabolic steroids. In both subjects, hair analysis showed positive results for stanozolol (135 and $156 \mathrm{pg} / \mathrm{mg}$ ), nandrolone (196 and $260 \mathrm{pg} / \mathrm{mg}$ ), and testosterone (46 and $71 \mathrm{pg} / \mathrm{mg}$ ), which clearly indicated chronic exposure to anabolic drugs (Nakahara et al. 1990). Various other performance-enhancing drugs have also been identified in the hair, such as beta-adrenergic drugs (agonists and antagonists) (Kintz et al. 1995a), ephedrine (Nakahara et al. 1992b) or corticosteroids (Nakahara et al. 1992a; Wester et al. 2017; White 1990), and clostebol (Salomone et al. 2018).

\section{Drug screening for pre-employment and driving license fitness testing}

For fitness testing before employment and driving license issuance, hair testing is the best option used to verify the drug abuse history. Segmental analysis of hair can confirm the abuse of a drug in the past few months (Ricossa et al. 2000). Level of drug abuse, single, multiple, or chronic users can also be confirmed (Wang et al. 2018). Driving under the influence of psychotropic substances is a life-threatening matter for the driver as well as for the passers-by. Hair analysis in combination with psychological tests can help to trace out the drug abuse history, which can be used for re-granting or canceling the license (Kintz et al. 2006; Lendoiro et al. 2018). The applicants having drug abuse history have to prove fitness and undergo a physical examination. Urine and hair samples are collected and analyzed for the presence of amphetamines, barbiturates, benzodiazepines, cocaine, and opiates (Tagliaro et al. 1997a). Studies showed that hair analysis is more effective than urinalysis for "fitness to drive assessment" (Furrer et al. 2017). Montagana developed a sensitive GC-MS method for the investigation of cocaine, opiates, and their metabolites from the hair of driving license applicants with drug addiction history (Montagna et al. 2000).

\section{Post-mortem toxicology}

In post-mortem toxicology, there are a number of biological samples (blood, muscles, lung, fat, or any other body tissue) for analysis to determine the cause of death. For forensic investigation, it is helpful to gain maximum possible information regarding the victim's regular use of drugs before death (Høiseth et al. 2017). Some drugs, which are unstable in post-mortem conditions, e.g., cocaine, morphine, heroin, benzodiazepines, and glucuronide can be determined by the presence of metabolites (Drummer 2004). The presence of a drug or its metabolite in the hair can confirm whether the person was a regular user of a drug or not (Skopp 2010).

\section{Metal toxicity}

Metal toxicity can cause different diseases and even death. Like drug deposition, metals also get deposited in the hair. The metals can be analyzed by atomic absorption spectroscopy (AAS) and ICP-MS (Ash and $\mathrm{He}$ 2018). Recently, the presence of mercury in the hair of ancient mummies was studied positively (Arnold et al. 2018). Peter analyzed hair samples for heavy metals (As, $\mathrm{Cr}, \mathrm{Cd}$, and $\mathrm{Pb}$ ) across various occupational distributions and gender by using AAS technique. The concentrations 
of metal were measured, and mean concentration values in milligram per kilogram were $\mathrm{As}=222 \pm 34.1, \mathrm{Cr}=$ $2.70 \pm 0.7, \quad \mathrm{Cd}=27.8 \pm 8.0$, and $\mathrm{Pb}=73.8 \pm 42.3$. Also, there was a difference in concentrations of metals in both the genders. The individual differences, living style, and exposure to heavy metals could be some causes of difference in concentrations (Peter et al. 2012). Barreera used acidified digestion of hair by using microwave energy to determine the concentrations of $\mathrm{Cu}, \mathrm{Zn}, \mathrm{Fe}, \mathrm{Mg}$, and $\mathrm{Ca}$ by flame atomic absorption spectroscopy (FAAS) and $\mathrm{Mn}$ by electrothermal atomic absorption spectrometry (ETAAS) (Bermejo-Barrera et al. 2000).

\section{Conclusion}

Hair analysis has a number of applications in forensic toxicology, clinical toxicology, occupational medicine, and doping control. The major practical advantage of hair analysis for testing drugs as compared to urine and blood is its larger detection window. For hair analysis, drugs can be detected even after months, depending on the length of the hair shaft analyzed, against a few days for urine. In practice, detection window offered by urine and hair testing is complementary: urine analysis provides short-term information on an individual's drug use, whereas long-term history is accessible through hair analysis. Although there is a reasonable agreement that the qualitative results from hair analysis are valid. The interpretation of the results is still under debate because of some unresolved questions, such as the influence of external contamination or cosmetic treatment and possible genetic differences (White et al. 1993). Hair analysis depicts the usage of drugs for several months. Hair can show the accurate result for amphetamine and cocaine if these drugs were abused weekly but cannot find out accurately even the daily abuse of cannabis. The cost for hair drug analysis is highest while the lowest for urine (Gjerde et al. 2011).

\section{Abbreviations \\ AAS: Atomic absorption spectroscopy; CBD: Cannabidiol; CBN: Cannabinol; CZE: Capillary zone electrophoresis; DFSA: Drug-facilitated sexual assault; ELISA: Enzyme-linked immunosorbent assay; FID: Flame ionization detector; GC-MS: Gas chromatography-mass spectroscopy; GHB: Gamma- hydroxybutyrate; LC-MS: Liquid chromatography-mass spectroscopy; LOD: Limit of detection; MAM: Monoacetylmorphine; MBDB: Methylbenzodioxazolylbutanamine: \\ MDA: Methylenedioxyamphetamine; \\ MDMA: Methylenedioxymethamphetamine; RIA: Radioimmunoassay; SFE: Supercritical fluid extraction; SIM: Single ion mode; SPE: Solid phase extraction; THC: Tetrahydrocannabinol; TLC: Thin layer chromatography}

\section{Acknowledgements}

None.

Funding

None.

Availability of data and materials

Not Required.

\section{Authors' contributions}

$\mathrm{MU}$ is the main author and contributor of this review article. AN, YB, TJ, MS and SK helped in editingthe manuscript. All authors read and approved the final manuscript.

\section{Authors' information}

Muhammad Usman completed his MS Forensic Chemistry (2014) from Government College University Lahore and joined Punjab Forensic Science Agency (PFSA) in August 2014 as Junior Forensic Scientist at Narcotic Unit. At Narcotic Unit, PFSA Lahore, he is responsible for analysis of Narcotic Evidence (Seized Narcotic Drugs e.g. Hashish, Cannabis, Opium, Heroin, Poppy Plants, Amphetamine type stimulant and Narcotic Tablets/Injections) provided by Law Enforcement Agencies \& Court of Law and to testify in court as Expert Witness. Furthermore, he has been engaged in conducting the research and interprets literature on criminal laboratory analytical methods; keep current on techniques and trends; to research and develop new analytical methods and modification of already existing methods for better production of results.

During his short professional career, he have attended various workshops and conferences at national and international level related to forensic

science in order to get in touch the current progress in forensic science.

Ethics approval and consent to participate

Not Required - This is a review article.

Consent for publication

Not Required - This is a review article.

Competing interests

The author declares that he has no competing interests.

\section{Publisher's Note}

Springer Nature remains neutral with regard to jurisdictional claims in published maps and institutional affiliations.

\section{Author details}

${ }^{1}$ Narcotic Unit, Punjab Forensic Science Agency, Lahore 53700, Pakistan.

2Department of Chemisty, GCU Lahore, Lahore, Pakistan.

Received: 4 April 2018 Accepted: 11 March 2019

Published online: 27 April 2019

\section{References}

Allen DL, Oliver JS (2000) The use of supercritical fluid extraction for the determination of amphetamines in hair. Forensic Sci Int 107:191-199

Allibe N, Kintz P, Faure A, Paysant F, Michard-Lenoir A-P, Stanke-Labesque F, Scolan V, Eysseric-Guerin H (2017) Interest of single hair analysis to document drug exposure: literature review and a case report involving zuclopenthixol. Curr Pharm Des 23:5502-5510

Arnold S, Parker J, Bloom N, Aufderheide A, Middaugh J (2018) Mercury in ancient mummy hair from Peru, Chile, and Egypt-Evidence of pre-industrial naturally occurring dietary exposure May 22, 2018

Ash R, He M (2018) Details of a thallium poisoning case revealed by single hair analysis using laser ablation inductively coupled plasma mass spectrometry. Forensic Sci Int 292: 224-231

Baptista M, Monsanto PV, Pinho Marques E, Bermejo A, Avila S, Castanheira AM, Margalho C, Barroso M, Vieira DN (2002) Hair analysis for D9-THC, D9-THC$\mathrm{COOH}, \mathrm{CBN}$ and CBD, by GC/MS-El. Forensic Sci Int 128:66-78

Barker J, Petroczi A, Naughton D, Breidi S (2017) False positive drug results by ELISA associated with enzymatic hair digestion. Open Access J Toxicol 1: 555560

Baumgartner AM, Jones PF, Baumgartner WA, Black CT (1979) Radioimmunoassay of hair for determining opiate-abuse histories. J Nucl Med 20:748-752

Baumgartner MR, Guglielmello R, Fanger M, Kraemer T (2012) Analysis of drugs of abuse in hair: evaluation of the immunochemical method VMA-T vs. LC-MS/ MS or GC-MS. Forensic Sci Int 215:56-59

Baumgartner WA, Hill V, Blahd WH (1989) Hair analysis for drugs of abuse. J Forensic Sci 34:1433-1453

Bermejo-Barrera P, Muñiz-Naveiro O, Moreda-Piñeiro A, Bermejo-Barrera A (2000) Experimental designs in the optimisation of ultrasonic bath-acidleaching procedures for the determination of trace elements in human 
hair samples by atomic absorption spectrometry. Forensic Sci Int 107 105-120

Blank DL, Kidwell DA (1995) Decontamination procedures for drugs of abuse in hair: are they sufficient? Forensic Sci Int 70:13-38

Busardò FP, Pichini S, Zaami S, Pacifici R, Kintz P (2018) Hair testing of GHB: an everlasting issue in forensic toxicology. Clin Chem Lab Med 56:198-208

Cartmell LW, Aufderhide A, Weems C (1991) Cocaine metabolites in preColumbian mummy hair. J Okla State Med Assoc 84:11-12

Cirimele V, Kintz P, Dumestre V, Goulle J, Ludes B (2000) Identification of ten corticosteroids in human hair by liquid chromatography-ionspray mass spectrometry. Forensic Sci Int 107:381-388

Cirimele V, Kintz P, Ludes B (1999) Mise en evidence de l'exposition aux pesticides par analyse des cheveux. Acta Clin Belg Suppl 1:59-63

Cirimele V, Kintz P, Mangin P (1995) Drug concentrations in human hair after bleaching. J Anal Toxicol 19:331-332

Cirimele V, Kintz P, Mangin P (1996a) Detection and quantification of lorazepam in human hair by GC-MS/NCI in a case of traffic accident. Int J Legal Med 108:265-267

Cirimele V, Sachs H, Kintz P, Mangin P (1996b) Testing human hair for cannabis. III. Rapid screening procedure for the simultaneous identification of $\Delta 9$ tetrahydrocannabinol, cannabinol, and cannabidiol. J Anal Toxicol 20:13-16

Cone EJ (1996) Mechanisms of drug incorporation into hair. Ther Drug Monit 18: 438-443

Cone EJ, Yousefnejad D, Darwin WD, Maguire T (1991) Testing human hair for drugs of abuse. II. Identification of unique cocaine metabolites in hair of drug abusers and evaluation of decontamination procedures. J Anal Toxicol 15:250-255

Cooper GA, Kronstrand R, Kintz P (2012) Society of hair testing guidelines for drug testing in hair. Forensic Sci Int 218:20-24

Cuypers E, Flanagan RJ (2018) The interpretation of hair analysis for drugs and drug metabolites. Clin Toxicol 56:90-100

Dinis-Oliveira RJ, Magalhães T (2013) Forensic toxicology in drug-facilitated sexual assault. Toxicol Mech Methods 23:471-478

Drummer OH (2004) Postmortem toxicology of drugs of abuse. Forensic Sci Int 142:101-113

Edder P, Staub C, Veuthey J-L, Pierroz I, Haerdi W (1994) Subcritical fluid extraction of opiates in hair of drug addicts. J Chromatogr B Biomed Sci Appl 658:75-86

Forman R, Schneiderman J, Klein J, Graham K, Greenwald M, Koren G (1992) Accumulation of cocaine in maternal and fetal hair; the dose response curve. Life Sci 50:1333-1341

Franceschin A, Morosini L, Dell'Anna L (1987) Detection of morphine in hair with the Abbott TDX. Clin Chem 33:2125-2125

Furrer L, Jackowski C, Pfäffli M (2017) Cocaine testing in fitness-to-drive assessments: comparison between hair analysis, urinalysis and self-reports. Alcohol Drug Addict 30:103-112

Gjerde H, Øiestad EL, Christophersen AS (2011) Using biological samples in epidemiological research on drugs of abuse. Norsk Epidemiologi 21(1):5-14

Gottardo R, Fanigliulo A, Bortolotti F, De Paoli G, Pascali JP, Tagliaro F (2007) Broadspectrum toxicological analysis of hair based on capillary zone electrophoresistime-of-flight mass spectrometry. J Chromatogr A 1159:190-197

Goullé JP, Chèze M, Pépin G (2003) Determination of endogenous levels of GHB in human hair. Are there possibilities for the identification of GHB administration through hair analysis in cases of drug-facilitated sexual assault? J Anal Toxicol 27:574-580

Harrison R, Fu S (2014) A review of methodology for testing hair for cocaine. J Forensic Invest 2:1-7

Hegstad S, Khiabani H, Kristoffersen L, Kunøe N, Lobmaier P, Christophersen A (2008) Drug screening of hair by liquid chromatography-tandem mass spectrometry. J Anal Toxicol 32:364-372

Henderson G (1993) Mechanisms of drug incorporation into hair. Forensic Sci Int 63:19-29

Henderson GL, Harkey MR, Zhou C, Jones RT, Jacob P III (1996) Incorporation of isotopically labeled cocaine and metabolites into human hair: 1. Dose-response relationships. J Anal Toxicol 20:1-12

Henderson GL, Harkey MR, Zhou C, Jones RT, Jacob P III (1998) Incorporation of isotopically labeled cocaine into human hair: race as a factor. J Anal Toxicol 22:156-165

Høiseth G, Arnestad M, Karinen R, Morini L, Rogde S, Sempio C, Vindenes V, Øiestad ÅML (2017) Is hair analysis useful in postmortem cases? J Anal Toxicol 42:49-54
Höld KM, Borges CR, Wilkins DG, Rollins DE, Joseph RE Jr (1999) Detection of nandrolone, testosterone, and their esters in rat and human hair samples. $J$ Anal Toxicol 23:416-423

Huang DK, Liu C, Huang MK, Chien CS (2009) Simultaneous determination of morphine, codeine, 6-acetylmorphine, cocaine and benzoylecgonine in hair by liquid chromatography/electrospray ionization tandem mass spectrometry. Rapid Commun Mass Spectrom 23:957-962

Huestis MA, Gustafson RA, Moolchan ET, Barnes A, Bourland JA, Sweeney SA, Hayes EF, Carpenter PM, Smith ML (2007) Cannabinoid concentrations in hair from documented cannabis users. Forensic Sci Int 169:129-136

Jeger A, Raas R, Hamberg C, Briellmann T (1991) Morphin-determination in human hair by instrumental HP-TLC. In: TIAFT proceedings, pp 250-256

Johansen SS, Jornil J (2009) Determination of amphetamine, methamphetamine, MDA and MDMA in human hair by GC-EI-MS after derivatization with perfluorooctanoyl chloride. Scand J Clin Lab Invest 69:113-120

Jurado C, Gimenez M, Menendez M, Repetto M (1995) Simultaneous quantification of opiates, cocaine and cannabinoids in hair. Forensic Sci Int 70:165-174

Jurado C, Soriano T, Menendez M, Repetto M (2000) Comparative efficiency of hair and urine analysis when assessing drug consumption. Probl Forensic Sci XLII:137-142

Kalasinsky KS, Magluilo J Jr, Schaefer T (1994) Study of drug distribution in hair by infrared microscopy visualization. J Anal Toxicol 18:337-341

Karačonji IB, Brajenović N (2014) Evaluation of amphetamine-type stimulant abuse through hair analysis: results from 12 years of work. Arch Ind Hyg Toxicol 65:225-230

Kauert G, Röhrich J (1996) Concentrations of $\Delta$ 9-tetrahydrocannabinol, cocaine and 6-monoacetylmorphine in hair of drug abusers. Int J Legal Med 108:294-299

Khajuria H, Nayak B (2013) Detection of drug of abuse (morphine) in hair. Res J Forensic Sci 1:18-20

Khajuria $\mathrm{H}$, Nayak BP (2014) Detection of $\Delta$ 9-tetrahydrocannabinol (THC) in hair using GC-MS. Egypt J Forensic Sci 4:17-20

Khajuria H, Nayak BP (2017) Hair: a bio-marker for detection of drugs of abuse. Asian J Psychiatr 30:208-209

Khajuria H, Nayak BP, Badiye A (2018) Toxicological hair analysis: pre-analytical, analytical and interpretive aspects. Med Sci Law 58:137-146

Kidwell D (1993) Analysis of phencyclidine and cocaine in human hair by tandem mass spectrometry. J Forensic Sci 38:272-284

Kikura R, Nakahara Y, Mieczkowski T, Tagliaro F (1997) Hair analysis for drug abuse $X V$. Disposition of 3, 4-methylenedioxymethamphetamine (MDMA) and its related compounds into rat hair and application to hair analysis for MDMA abuse. Forensic Sci Int 84:165-177

Kim JY, Suh S, In MK, Paeng K-J, Chung BC (2005) Simultaneous determination of cannabidiol, cannabinol, and $\backslash g D$ 9tetrahydrocannabinol in human hair by gas chromatography-mass spectrometryin human hair by gas chromatography-mass spectrometry. Arch Pharm Res 28:1086-1091

Kintz P (2017a) Evidence of 2 populations of mephedrone abusers by hair testing. Application to 4 forensic expertises. Curr Neuropharmacol 15:658-662

Kintz P (2017b) Hair analysis in forensic toxicology: an updated review with a special focus on pitfalls. Curr Pharm Des 23:5480-5486

Kintz P, Ameline A, Eibel A, Gheddar L, Feisthauer E, Geraut A, Berthelon L, Farrugia A, Raul J-S (2017) Interpretation of Cannabis findings in the hair of very young children: Mission impossible. Curr Pharm Biotechnol 18:791-795

Kintz P, Cirimele V, Ludes B (2000a) Pharmacological criteria that can affect the detection of doping agents in hair. Forensic Sci Int 107:325-334

Kintz P, Cirimele V, Mangin P (1995a) Testing human hair for cannabis II. Identification of THC-COOH by GC-MS-NCI as a unique proof. J Forensic Sci 40:619-622

Kintz P, Cirimele V, Sachs H, Jeanneau T, Ludes B (1999) Testing for anabolic steroids in hair from two bodybuilders. Forensic Sci Int 101:209-216

Kintz P, Cirimele V, Sengler C, Mangin P (1995b) Testing human hair and urine for anhydroecgonine methyl ester, a pyrolysis product of cocaine. J Anal Toxicol 19:479-482

Kintz P, Cirimele V, Tracqui A, Mangin P (1995C) Simultaneous determination of amphetamine, methamphetamine, 3, 4-methylenedioxyamphetamine and 3, 4-methylenedioxymethamphetamine in human hair by gas chromatography-mass spectrometry. J Chromatogr B Biomed Sci Appl 670:162-166

Kintz P, Dumestre-Toulet V, Jamey C, Cirimele V, Ludes B (2000b) Doping control for $\beta$-adrenergic compounds through hair analysis. J Forensic Sci 45:170-174 
Kintz P, Kieffer I, Messer J, Mangin P (1993) Nicotine analysis in neonates' hair for measuring gestational exposure to tobacco. J Forensic Sci 38:119-123

Kintz P, Villain M, Cirimele V (2006) Hair analysis for drug detection. Ther Drug Monit 28:442-446

Kintz P, Villain M, Ludes B (2004) Testing for the undetectable in drug-facilitated sexual assault using hair analyzed by tandem mass spectrometry as evidence. Ther Drug Monit 26:211-214

Klein J, Karaskov T, Koren G (2000) Clinical applications of hair testing for drugs of abuse-the Canadian experience. Forensic Sci Int 107:281-288

Klug E (1980) Zur Morphinbestimmung in kopfhaaren. Z Rechtsmed 84:189-193

Kronstrand R, Förstberg-Peterson S, KÅgedal B, Ahlner J, Larson G (1999) Codeine concentration in hair after oral administration is dependent on melanin content. Clin Chem 45:1485-1494

Kuwayama K, Nariai M, Miyaguchi H, Iwata YT, Kanamori T, Tsujikawa K, Yamamuro T, Segawa H, Abe H, Iwase H (2018) Micro-segmental hair analysis for proving drug-facilitated crimes: evidence that a victim ingested a sleeping aid, diphenhydramine, on a specific day. Forensic Sci Int 288:23-28

LeBeau M, Montgomery M (2010) Challenges of drug-facilitated sexual assault. Forensic science review 22:1-6

Lendoiro E, de Castro A, Jiménez-Morigosa C, Gomez-Fraguela XA, LópezRivadulla M, Cruz A (2018) Usefulness of hair analysis and psychological tests for identification of alcohol and drugs of abuse consumption in driving license regranting. Forensic Sci Int 286:239-244

Lendoiro E, Quintela Ó, de Castro A, Cruz A, López-Rivadulla M, Concheiro M (2012) Target screening and confirmation of 35 licit and illicit drugs and metabolites in hair by LC-MSMS. Forensic Sci Int 217:207-215

Leung KW, Wong ZC, Ho JY, Yip AW, Cheung JK, Ho KK, Duan R, Tsim KW (2018) Surveillance of drug abuse in Hong Kong by hair analysis using LC-MS/MS. Drug Test Anal 10:977-983

Machnik M, Geyer H, Horning S, Breidbach A, Delahaut P, Schänzer W (1999) Long-term detection of clenbuterol in human scalp hair by gas chromatography-high-resolution mass spectrometry. J Chromatogr B Biomed Sci Appl 723:147-155

Mangin P (1996) Drug analysis in nonhead hair. In: Drug testing in hair, pp 279-287

Mantinieks D, Gerostamoulos D, Wright P, Drummer O (2018) The effectiveness of decontamination procedures used in forensic hair analysis. Forensic Sci Med Pathol:1-9

Maublanc J, Dulaurent S, Imbert L, Kintz P, Gaulier J-M (2014) Unusual pattern in hair after prazepam exposure. Toxicol Anal Clin 26:24-26

Meng P, Zhu D, He H, Wang Y, Guo F, Zhang L (2009) Determination of amphetamines in hair by GC/MS after small-volume liquid extraction and microwave derivatization. Anal Sci 25:1115-1118

Mercolini L, Mandrioli R, Protti M, Conti M, Serpelloni G, Raggi MA (2013) Monitoring of chronic Cannabis abuse: an LC-MS/MS method for hair analysis. J Pharm Biomed Anal 76:119-125

Mercolini L, Mandrioli R, Saladini B, Conti M, Baccini C, Raggi MA (2008) Quantitative analysis of cocaine in human hair by HPLC with fluorescence detection. J Pharm Biomed Anal 48:456-461

Miki A, Katagi M, Tsuchihashi H (2003) Determination of methamphetamine and its metabolites incorporated in hair by column-switching liquid chromatography-mass spectrometry. J Anal Toxicol 27:95-102

Miller El, Wylie FM, Oliver JS (2006) Detection of benzodiazepines in hair using ELISA and LC-ESI-MS-MS. J Anal Toxicol 30:441-448

Miller El, Wylie FM, Oliver JS (2008) Simultaneous detection and quantification of amphetamines, diazepam and its metabolites, cocaine and its metabolites, and opiates in hair by LC-ESI-MS-MS using a single extraction method. J Anal Toxicol 32:457-469

Moeller M, Fey P, Sachs H (1993) Hair analysis as evidence in forensic cases. Forensic Sci Int 63:43-53

Moeller M, Maurer H, Roesler M (1992) MDMA in blood, urine and hair: a forensic case. In: Proceedings of the 30th international meeting of the international association of forensic toxicologists, Fukuoka, Japan, pp 347-361

Moeller MR (1992) Drug detection in hair by chromatographic procedures. J Chromatogr B Biomed Sci Appl 580:125-134

Möller M, Fey P, Rimbach S (1992) Identification and quantitation of cocaine and its metabolites, benzoylecgonine and ecgonine methyl ester, in hair of Bolivian coca chewers by gas chromatography/mass spectrometry. J Anal Toxicol 16:291-296

Montagna M, Stramesi C, Vignali C, Groppi A, Polettini A (2000) Simultaneous hair testing for opiates, cocaine, and metabolites by GC-MS: a survey of applicants for driving licenses with a history of drug use. Forensic Sci Int 107: 157-167

Montesano C, Vannutelli G, Massa M, Simeoni MC, Gregori A, Ripani L, Compagnone D, Curini R, Sergi M (2017) Multi-class analysis of new psychoactive substances and metabolites in hair by pressurized liquid extraction coupled to HPLC-HRMS. Drug Test Anal 9:798-807

Musshoff F, Kirschbaum K, Graumann K, Herzfeld C, Sachs H, Madea B (2012) Evaluation of two immunoassay procedures for drug testing in hair samples. Forensic Sci Int 215:60-63

Nakahara Y, Shimamine M, Takahashi K (1992a) Hair analysis for drugs of abuse. III. Movement and stability of methoxyphenamine (as a model compound of methamphetamine) along hair shaft with hair growth. J Anal Toxicol 16:253-257

Nakahara Y, Takahashi K, Shimamine M, Saitoh A (1992b) Hair analysis for drugs of abuse. IV. Determination of total morphine and confirmation of 6 acetylmorphine in monkey and human hair by GC/MS. Arch Toxicol 66:669-674

Nakahara Y, Takahashi K, Takeda Y, Konuma K, Fukui S, Tokui T (1990) Hair analysis for drug abuse, part II. Hair analysis for monitoring of methamphetamine abuse by isotope dilution gas chromatography/mass spectrometry. Forensic Sci Int 46:243-254

Negrusz A, Bowen AM, Moore CM, Dowd SM, Strong MJ, Janicak PG (2002) Deposition of 7-aminoclonazepam and clonazepam in hair following a single dose of Klonopin ${ }^{\mathrm{TM}}$. J Anal Toxicol 26:471-478

Negrusz A, Moore CM, Hinkel KB, Stockham TL, Verma M, Strong MJ, Janicak PG (2001) Deposition of 7-aminoflunitrazepam and flunitrazepam in hair after a single dose of Rohypnol ${ }^{\oplus}$. J Forensic Sci 46:1143-1151

Orfanidis A, Mastrogianni O, Koukou A, Psarros G, Gika H, Theodoridis G, Raikos N (2017) A GC-MS method for the detection and quantitation of ten major drugs of abuse in human hair samples. J Chromatogr B 1047:141-150

Pelander A, Ristimaa J, Rasanen I, Vuori E, Ojanperä I (2008) Screening for basic drugs in hair of drug addicts by liquid chromatography/time-of-flight mass spectrometry. Ther Drug Monit 30:717-724

Peter OO, Eneji IS, Sha'Ato R (2012) Analysis of heavy metals in human hair using atomic absorption spectrometry (AAS). Am J Anal Chem 3:770

Pötsch L, Skopp G, Moeller M (1997) Zum Suchtmittelnachweis in Haaren. Rechtsmedizin 7:1-5

Pragst F, Balikova MA (2006) State of the art in hair analysis for detection of drug and alcohol abuse. Clin Chim Acta 370:17-49

Pragst F, Hastedt M, Krumbiegel F, Herre S (2015) Hair analysis as a diagnostic and forensic tool in a social support system for families with underage children and drug abusing parents: a four year experience. Arab J Forensic Sci Forensic Med 1:180-193

Quintela O, Bermejo A, Tabernero M, Strano-Rossi S, Chiarotti M, Lucas A (2000) Evaluation of cocaine, amphetamines and cannabis use in university students through hair analysis: preliminary results. Forensic Sci Int 107:273-279

Ricossa MC, Bernini M, De Ferrari F (2000) Hair analysis for driving licence in cocaine and heroin users: an epidemiological study. Forensic Sci Int 107:301-308

Rothe M, Pragst F, Spiegel K, Harrach T, Fischer K, Kunkel J (1997) Hair concentrations and self-reported abuse history of 20 amphetamine and ecstasy users. Forensic Sci Int 89:111-128

Sachs H (2000) Consensus of the Society of Hair Testing on hair testing for doping agents. Forensic Sci Int 107:3

Sachs H, Arnold W (1989) Results of comparative determination of morphine in human hair using RIA and GC/MS. Clin Chem Lab Med 27:873-878

Sachs H, Kintz P (1998) Testing for drugs in hair: critical review of chromatographic procedures since 1992. J Chromatogr B Biomed Sci Appl 713:147-161

Saitoh M (1969) Rate of hair growth. Adv Biol Ski 9:183-202

Salomone A, Gerace E, Di Corcia D, Alladio E, Vincenti M, Kintz P (2018) Hair analysis can provide additional information in doping and forensic cases involving clostebol. Drug Test Anal

Shearer J, White B, Gilmour S, Wodak AD, Dolan KA (2006) Hair analysis underestimates heroin use in prisoners. Drug Alcohol Rev 25:425-431

Skopp G (2010) Postmortem toxicology. Forensic Sci Med Pathol 6:314-325

Strano-Rossi S, Botrè F, Bermejo AM, Tabernero MJ (2009) A rapid method for the extraction, enantiomeric separation and quantification of amphetamines in hair. Forensic Sci Int 193:95-100

Tabernero MJ, Felli ML, Bermejo AM, Chiarotti M (2009) Determination of ketamine and amphetamines in hair by LC/MS/MS. Anal Bioanal Chem 395:2547 
Tagliaro F, De Battisti Z, Lubli G, Neri C, Manetto G, Marigo M (1997a) Integrated use of hair analysis to investigate the physical fitness to obtain the driving licence: a casework study. Forensic Sci Int 84:129-135

Tagliaro F, Smith F, De Battisti Z, Manetto G, Marigo M (1997b) Hair analysis, a novel tool in forensic and biomedical sciences: new chromatographic and electrophoretic/electrokinetic analytical strategies. J Chromatogr B Biomed Sci Appl 689:261-271

Thieme D, Grosse J, Sachs H, Mueller R (2000) Analytical strategy for detecting doping agents in hair. Forensic Sci Int 107:335-345

Uhl M (1997) Determination of drugs in hair using GC/MS/MS. Forensic Sci Int 84 281-294

Villain M, Muller J-F, Kintz P (2010) Heroin markers in hair of a narcotic police officer: active or passive exposure? Forensic Sci Int 196:128-129

Wang X, Johansen SS, Nielsen MKK, Linnet K (2017) Targeted analysis of 116 drugs in hair by UHPLC-MS/MS and its application to forensic cases. Drug Test Anal 9:1137-115

Wang X, Johansen SS, Nielsen MKK, Linnet K (2018) Hair analysis in toxicological investigation of drug-facilitated crimes in Denmark over a 8-year period. Forensic Sci Int 285:e1-e12

Wester VL, Noppe G, Savas M, van den Akker EL, de Rijke YB, van Rossum EF (2017) Hair analysis reveals subtle HPA axis suppression associated with use of local corticosteroids: the lifelines cohort study. Psychoneuroendocrinology 80:1-6

White HR (1990) The drug use-delinquency connection in adolescence

White H.R., Brick J., Hansell S. (1993) A longitudinal investigation of alcohol use and aggression in adolescence. J Stud Alcohol, Supplement:62-77

Xiang P, Sun Q, Shen B, Chen P, Liu W, Shen M (2011) Segmental hair analysis using liquid chromatography-tandem mass spectrometry after a single dose of benzodiazepines. Forensic Sci Int 204:19-26

\section{Submit your manuscript to a SpringerOpen ${ }^{\circ}$ journal and benefit from:}

- Convenient online submission

- Rigorous peer review

- Open access: articles freely available online

- High visibility within the field

- Retaining the copyright to your article

Submit your next manuscript at $\boldsymbol{\nabla}$ springeropen.com 